GLOBAL RESEARCH ETHICS

\title{
Ethical review of health research: a perspective from developing country researchers
}

\author{
A A Hyder, S A Wali, A N Khan, N B Teoh, N E Kass, L Dawson
}

J Med Ethics 2004;30:68-72. doi: 10.1136/jme.2002.001933

See end of article for authors' affiliations

.....................

Correspondence to: A Hyder, Bloomberg School of Public Health, Johns Hopkins University, $615 \mathrm{~N}$ Wolfe St, E-8132 Baltimore, MD, USA; ahyder@jhsph.edu

Received

26 September 2002

Revised 12 February 2003

Accepted

28 February 2003
Background: Increasing collaboration between industrialised and developing countries in human research studies has led to concerns regarding the potential exploitation of resource deprived countries. This study, commissioned by the former National Bioethics Advisory Commission of the United States, surveyed developing country researchers about their concerns and opinions regarding ethical review processes and the performance of developing country and US international review boards (IRBs).

Methods: Contact lists from four international organisations were used to identify and survey 670 health researchers in developing countries. A questionnaire with 169 questions explored issues of IRB review, informed consent, and recommendations.

Results: The majority of the developing country researchers were middle aged males who were physicians and were employed by educational institutions, carrying out research on part time basis. Forty four percent of the respondents reported that their studies were not reviewed by a developing country IRB or Ministry of Health and one third of these studies were funded by the US. During the review process issues such as the need for local language consent forms and letters for approval, and confidentiality protection of participants were raised by US IRBs in significantly higher proportions than by host country IRBs.

Conclusion: This survey indicates the need for the ethical review of collaborative research in both US and host countries. It also reflects a desire for focused capacity development in supporting ethical review of research.

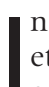
recent years, controversies have erupted concerning the ethics of biomedical research sponsored by wealthy nations and conducted in resource poor countries, generating debate and many editorial articles. ${ }^{1-5}$ However, little empirical research has been conducted on the ethics of research in developing countries, and thus limited information is available about the extent and nature of ethical problems encountered by researchers, or the application of human subject protection to research in these resource poor settings. The issues and concerns regarding ethical reviews in these collaborative research settings have also not been explored in detail.

We are aware of two previous small scale empirical studies, of largely US researchers, in this area. In 1994 Porter et al reported that researchers and administrators suggested that foreign based studies should have the same ethical review as US based studies, but the ethical guidelines should be made more appropriate for the host country. ${ }^{6}$ Another small scale survey, regarding the use of international single project assurances (SPAs) reported that US investigators bear some responsibility for the protection of human subjects who participate in their research projects in other countries, even if they have no direct contact with these subjects. ${ }^{7}$

Many of the recent publications in this arena are editorial pieces, and a large number address the issue of HIV/AIDS, ${ }^{8}$ especially in Africa, ${ }^{9-11}$ others discuss the interaction of Western clinical research ethics with non-Western cultural norms, and how potential conflicts arising from cultural differences are being resolved..$^{12}$ Ethicists have also written about their concerns regarding policies of multinational drug companies, indicating that they do not treat developed and developing countries equally. ${ }^{13}$ The active engagement of the sponsoring country as well as the host country in the review process has also been emphasised, and has been specified in recent ethical guidelines for international research. ${ }^{14}$ However, concerns have also been raised that the role of such ethical review boards in developing countries may fall short of promoting high ethical standards for human subject research, as they are poorly funded and lack properly trained staff. ${ }^{15}$

The purpose of this study was to explore the experiences and attitudes of researchers from developing countries regarding the role of institutional review boards (IRB) in ensuring the adequacy of ethical standards in research conducted in those countries. The process of IRB reviews, content of issues raised by these review boards, and the effectiveness of ethical guidelines have been explored. This study is part of a larger project that surveyed developing country and US researchers, some of whom worked on US funded projects, about their experiences and attitudes towards human subject regulations and the ethical issues that arise in their work. The larger project was initiated by the United States' National Bioethics Advisory Commission (NBAC) to inform their deliberations on international research ethics. ${ }^{16}$

\section{METHODS}

The study involved a self administered survey and was approved by the US Office of Management and Budget and by the Johns Hopkins Bloomberg School of Public Health Committee for Human Research. It consisted of nine sections with a total of 169 questions, covering IRB reviews; informed consent; relationships with collaborators; availability of interventions; general ethical issues; US and international rules and guidelines; description of the researchers' research studies (and experiences), and their recommendations. The survey questionnaire was peer reviewed by colleagues at

Abbreviations: IRB, international review board; NBAC, National Bioethics Advisory Commission 
Johns Hopkins University and developing country researchers visiting the US at that time.

The survey elicited responses based on general experience and opinions of researchers, as well as with specific reference to a current or recent (less than five years old) research project on which they had spent the most time during the past five years-referred to as the "index study". Questions related to IRB reviews of the studies will be reported in this paper. Funds for research studies were explored: studies having one or more sources of US funding were defined as US funded studies.

In the process of identifying developing country researchers, the term "developing country" required explicit definition. For the purposes of this study, a developing country has been defined using the criteria adopted by WHO's Ad Hoc Committee on Health Research Relating to Future Interventions Options. ${ }^{17}$ Developing country health researchers who work with human subjects number in the thousands and no single database lists such researchers. Therefore, four international organisations actively involved with developing country researchers, who maintain a publicly accessible database, were contacted to identify such researchers, namely: The International Clinical Epidemiology Network (INCLEN), Commission on Health Research for Development (COHRED), Scientists for Health And Research for Development (SHARED), and Health Systems Trust (HST). A master list was created from these databases after removing duplicate names and information on non-health researchers. To our knowledge, such a list of developing country researchers has never been previously constructed.

From the master list 670 researchers were contacted via email and invited to participate in the survey. 192 emails were returned undeliverable and the rest were followed up via email, mail, fax, and courier services. Fifty seven additional developing country researchers were contacted to complete the survey, referred by US researchers who were participating in the complementary US survey of NBAC. Five surveys were also completed by African researchers attending a Johns Hopkins international research ethics course in Malawi in March 2000. Invitation to participate in the survey was assumed to have reached 540 researchers. Researchers were given the option to complete the survey on the Internet or by filling out the paper version of the survey. Data collection took place over five months, between 18 November 1999 and 17 April 2000. An incentive of US\$25 was sent to those researchers who completed the minimum required sections on the survey.

Surveys completed via the Internet were stored in a Microsoft Access database, while those completed on paper were entered into EPI-INFO version 6.04b, 1997 (Centers for Disease Control and Protection, Atlanta, GA, USA). Double data entry and confirmatory crosschecks with the original response were used. Surveys in which three or more sections were answered were considered "complete" and were used for data analysis. These databases were merged and data editing and analysis done using Stata version 6.0 (1984-99 Stata Corporation, College Station, TX, USA) to determine frequency of responses by each variable and multivariate analyses to evaluate correlation of two or more variables. To measure the strength of association between variables, tests of significance, such as $\chi^{2}$ test and respective $p$ values, were calculated

\section{RESULTS}

A total of 235 surveys were received, of which 203 were considered complete and used for this analysis. The survey was designed such that there were skip patterns for some questions; therefore the number of responses $(\mathrm{n})$ varies for different questions. Most of the researchers (42\%) were from

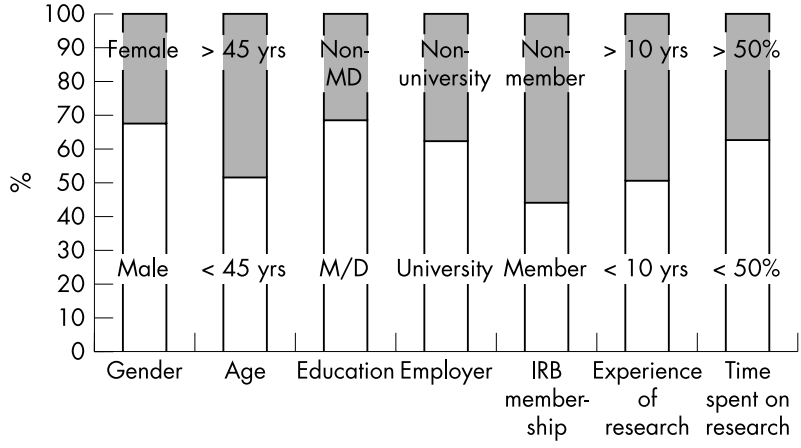

Figure 1 Sociodemographic information on developing country researchers $(n=203)$.

Asia, followed by Africa (29\%), and South America (23\%). Demographic information pertaining to respondents is shown in figure 1. More males comprised the sample as compared with females, and just over half were under 45 years old. The majority of survey respondents were physicians and employed by universities. Forty four percent of the researchers were or previously had been members of an IRB/ ethics board at either national, state, or local level. About half of the sample had more than ten years of research experience and $81 \%$ of the researchers had conducted more than five studies. Forty four percent of the index studies were funded by one or more US sources, and US non-profit organisations were the largest single funding source. Developing country sources funded $44 \%$ of the studies, whereas the private sector funded $15 \%$ of the studies overall.

Forty four percent of the survey respondents reported that their studies did not undergo any review (technical, scientific, or ethical) by a Ministry of Health in the developing country where the research was conducted (table 1). Twenty five percent of the respondents also reported that their studies did not undergo an ethics review by an IRB, ethics board, or Ministry of Health in the country. Further analyses showed that $15 \%$ of the studies being described in the survey were neither reviewed by the Ministry of Health nor by any ethics board in the developing country, of which one third were US funded. Of those studies funded by US sources, $12 \%$ were not reviewed by the country's own Ministry or Department of Health or an ethics board, while $17 \%$ of the non-US funded studies did not get any such review $(\mathrm{p}=0.7133)$.

Of the studies that were reviewed by IRBs, ethics board, or Ministry of Health, the majority (92\%) were reviewed at local institution level. A national ethics review board reviewed nearly half (49\%), and state/provincial ethics board reviewed

Table 1 Developing country IRBs and other ethics
review*

\begin{tabular}{llll}
\hline & $\mathrm{N}$ & $\%$ \\
\hline $\begin{array}{l}\text { The study did not undergo review by the Ministry/ } \\
\text { Department of Health in the country where the research }\end{array}$ & 82 & 44 \\
is/was conducted ( $\mathrm{n}=192$ ) \\
$\begin{array}{l}\text { The study did not undergo some type of ethics review by } \\
\text { an IRB, ethics board, or Ministry/Department of Health in } \\
\text { the country where the research is/was conducted ( } \mathrm{n}=185 \text { ) }\end{array}$ & 25 \\
$\begin{array}{l}\text { Studies which were neither reviewed by the Ministry/ } \\
\text { Department of Health nor by any IRB/ethics board }\end{array}$ & 28 & 15 \\
(n=184) & & \\
Studies which were neither reviewed by the Ministry/ \\
Department of Health nor by any IRB/ethics board and \\
were funded by the US ( $\mathrm{n}=28$ )
\end{tabular}


about one fourth $(27 \%)$ of the studies. Less than half $(43 \%)$ of respondents reported that it took one to two months to obtain approval and 35\% reported that it took three to six months. Of those researchers whose index study was funded by US sources, $69 \%$ responded that the developing country ethics review was required by US institutions for collaborative research. Developing country researchers reported that $44 \%$ of index studies were funded by US sources and $55 \%$ of these studies were reviewed by a US IRB. More than two thirds of these researchers reported that it took about one to six months for a study to be approved by a US IRB.

The researchers were asked to indicate which issues were raised by their IRBs (table 2 ). Developing country IRBs were most concerned about cultural appropriateness of the studies (59\%), need for local language consent form (58\%), relevance of research question to country where research was conducted $(54 \%)$, and the availability of intervention to host country after study was over (54\%). Researchers were also asked to report on their experiences with US IRB reviews. US IRBs were more likely to raise issues regarding: need for local language consent forms (84\%), need for letters of approval from developing country representatives $(79 \%)$, and complexity of the consent form (64\%).

Experiences and attitudes of developing country researchers towards US and international human subject regulations are shown in table 3. The majority (95\%) reported that US ethical guidelines ensure high ethical standards in research, and more than two thirds of the researchers agreed that developing country collaborators rely on US ethical regulations for guidance. Researchers also criticised some aspects of US ethical guidelines, as $83 \%$ of them responded that US IRB regulations were insensitive to local culture and more than half $(57 \%)$ agreed with the statement that US IRBs were more concerned with politics than with protecting the interests of research subjects. Nearly one third of the survey respondents said that US human subject regulations were never flexible where they needed to be, while $63 \%$ said they were either "always" or "sometimes" flexible. Developing country researchers were equally critical of developing country IRBs as they were of the US IRBs. When asked if
Table 3 Researchers' beliefs/attitudes about ethical guidelines and regulations in human subject research

\begin{tabular}{lccc}
\hline $\begin{array}{l}\text { Researchers' beliefs/attitudes about } \\
\text { ethical guidelines }\end{array}$ & $\begin{array}{c}\text { Never } \\
(\%)\end{array}$ & $\begin{array}{c}\text { Sometimes } \\
(\%)\end{array}$ & $\begin{array}{c}\text { Always } \\
(\%)\end{array}$ \\
\hline $\begin{array}{l}\text { US human subject regulations are } \\
\text { flexible where they need to be ( } n=72)\end{array}$ & $27(37)$ & $40(56)$ & $5(7)$ \\
$\begin{array}{l}\text { US IRBs are more concerned with } \\
\text { politics than they are with protecting }\end{array}$ & $29(43)$ & $37(54)$ & $2(3)$ \\
the interests of research subjects \\
(n=68)
\end{tabular}

developing country IRBs are more concerned with politics than they are with protecting the interests of research subjects, sixty three percent agreed. When asked whether the developing country IRBs have voiced concerns about the costs associated with IRB in carrying out its work, $45 \%$ of the researchers stated that it has been brought up. The majority $(92 \%)$ of survey respondents agreed that the national guidelines in developing countries are effective in protecting research subjects.

Researchers were also asked if they ever had to abandon a research project because it was impossible to get developing

Table 2 Comparison of responses to issues raised by US IRB(s) vis à vis issues raised by developing country IRB(s) for the same study

\begin{tabular}{|c|c|c|c|}
\hline Option & $\begin{array}{l}\text { Raised by developing country } \\
\text { IRB(s) or ethics board in its } \\
\text { review of the index study, } n(\%)\end{array}$ & $\begin{array}{l}\text { Raised by US IRB(s) } \\
\text { in its review of the } \\
\text { index study, } n(\%)\end{array}$ & p Value \\
\hline $\begin{array}{l}\text { Cultural appropriateness of study } \\
\text { procedure }\end{array}$ & $75 / 127(59)$ & $19 / 30(63)$ & 0.687 \\
\hline Need for local language consent form & $72 / 124(58)$ & $27 / 32(84)$ & $0.006^{*}$ \\
\hline $\begin{array}{l}\text { Relevance of research question to } \\
\text { country where research is conducted } \\
\text { and/or rationale for doing study outside } \\
\text { the US }\end{array}$ & $63 / 116(54)$ & $16 / 31(52)$ & 0.842 \\
\hline $\begin{array}{l}\text { Availability of intervention (if successful) } \\
\text { to host country after study is over }\end{array}$ & $51 / 95(54)$ & $11 / 24(46)$ & 0.483 \\
\hline $\begin{array}{l}\text { Need for letters of approval from } \\
\text { developing country representatives }\end{array}$ & $53 / 114(47)$ & $26 / 33(79)$ & $0.001^{*}$ \\
\hline $\begin{array}{l}\text { Complexity of language on consent } \\
\text { form }\end{array}$ & $54 / 120(45)$ & $18 / 28(64)$ & 0.070 \\
\hline $\begin{array}{l}\text { Appropriateness of procedures for } \\
\text { control group }\end{array}$ & $39 / 99(39)$ & $12 / 24(50)$ & 0.325 \\
\hline Use of placebos & $22 / 85(26)$ & $5 / 23(22)$ & 0.694 \\
\hline $\begin{array}{l}\text { Participant voluntaries may be } \\
\text { compromised because of benefits } \\
\text { study provides }\end{array}$ & $27 / 112(24)$ & $6 / 30(20)$ & 0.644 \\
\hline $\begin{array}{l}\text { Confidentiality protections for } \\
\text { participants were not adequate }\end{array}$ & $22 / 121(18)$ & $13 / 31(42)$ & $0.004^{*}$ \\
\hline Political considerations & $16 / 97(16)$ & $4 / 24(17)$ & 0.905 \\
\hline Intervention was considered too risky & $11 / 104(11)$ & $4 / 26(15)$ & 0.571 \\
\hline Others & $5 / 41(12)$ & $1 / 12(8)$ & 0.698 \\
\hline
\end{tabular}


country IRB approval despite modifications. Seventeen percent said that they had to abandon the research project; in contrast, only $6 \%$ reported having to abandon their project because it was impossible to obtain US IRB approval.

\section{DISCUSSION}

This study reflects the expressed opinions and attitudes of a sample of health researchers from the developing world and has provided an insight into the application of ethical reviews in resource poor settings. To our knowledge this is the first study of this nature with empirical data from developing country respondents. Respondents to this study reflect relatively senior researchers, the majority of whom are male physicians who conduct research on a part time basis.

It is heartening to note that the majority of research studies underwent an ethical review in the host country, which has been a stated standard for all research conducted in the developing world. ${ }^{18}$ However, one fourth of the respondents indicated that the index study had no ethics review in the country where the research was conducted, while nearly half indicated that their index studies were not reviewed by the Ministry of Health. Consequently, 15\% of the studies were neither reviewed by a ministry/department nor by an IRB at any level irrespective of the source of funding. Further analysis of this issue was limited in this survey as no alternatives were provided to explore the reasons why a review was not done. It is possible that these studies were believed to be "exempt" from review or that these were only reviewed by the collaborating institution in the West. However, it is likely that most of the studies were not reviewed at all. Ethics review in both the host and the donor country should be standard in collaborative research. However, a number of studies escaped the attention or need for ethics review in host countries; for example studies funded within the country by bilateral or international organisations were more likely not to have gone through standard review procedures. As a result, the processing of such studies through ethical review may need to be strengthened.

In responding to their impressions of the ethical reviews done by US IRBs, developing country researchers indicated that the type and complexity of documentation related to the study was an issue raised in a high percentage of cases; these include letters of approval and informed consent forms. Procedural issues, such as selection of control groups were also raised by US IRBs, whereas others such as political issues were raised less often. These results are more interesting when compared with the issues reportedly raised by developing country IRBs. In general, respondents indicated that most of the issues were raised more often by the US IRB than the developing country IRB (table 2). This was particularly seen in the informed consent process and protection of confidentiality, where significant differences were found. Issues raised more frequently by developing country IRBs include availability of any future interventions. Developing country respondents actually experience US IRBs raising more of each issue; this could be due to the greater expertise of US IRBs in conducting such reviews (and therefore a greater ability to detect issues), or their ability to compare procedures with standards used in the US (and therefore identify differences). Developing country IRBs may have had less experience in conducting such reviews and may lack set standards for comparison. In addition, respondents could have recalled the US IRB comments more than those of developing country IRB review, due to more attention paid to understanding US IRB comments and responding to them, or their own internal sensitivity to the critique of the US IRB. It is also possible that the US IRB review may have been the first one to occur chronologically and thus it had more issues to critique. This could also relate to the fact that issues pertaining to letters, language, and consent were significantly more frequent, as these comprise common procedural issues in research proposals. Subsequent reviews in the developing world would therefore tend to get a more developed proposal with several of the issues already addressed.

It is important to realise that the issue of cultural sensitivity is reported as a weakness within US ethical guidelines, as enforced in or viewed by developing country health researchers. Renewed stress within the US guidelines on appropriate cultural sensitivity in developing countries would make an impact on this opinion. Politics is viewed as playing a role in the functioning of both developing country and US IRBs; this is a serious perception, although it relies heavily on the interpretation of the word "politics". The work of both IRBs-US and developing country-should not be viewed by more than half of developing country respondents as even sometimes being influenced by any issue other than ethical or scientific in nature, as this opens the door for differential application of guidelines based on other US interests. The US guidelines need to respond to this concern in creating a new standard for the working of US IRBs where this issue is explicitly addressed, and likewise for national guidelines in developing countries.

Only one fifth of the researchers expressed the opinion that developing country guidelines are "always" able to protect research subjects. This lower proportion reflects a mixture of their absolute opinion, as well as their relative comparison with the US guidelines, which were rated much higher. It is important to note that the survey indicates that ethical guidelines in developing countries exist and are able to offer some protection to research subjects, which is different from the hypothesis that such local guidelines are either nonexistent or entirely worthless.

The process of ethical review in both the US and the developing world did not prevent a large majority of the research work from going forward. This is an important finding for proponents of research (often researchers themselves) who view ethical review processes as potential "barriers" to research. Only six percent of the responses indicated that a project had been abandoned due to lack of an ethical approval from a US IRB, while seventeen percent indicated the same for a developing country IRB $(p=0.010)$. In all, $22 \%$ of those respondents who answered both questions $(n=93)$ indicated that they had to abandon their research projects because it was impossible to get an IRB approval from either the developing country, US, or both. These percentages may include some cases that were unfairly judged, or the victims of overburdened bureaucracies and long time lags, but it is also likely that there were studies that should not have been given permission from an ethical viewpoint. And so the idea that all (100\%) studies should be approved after modification, assumes that all studies can be done ethically or that all scientific questions are worth asking. Even if it is assumed that good science is a prerequisite for good ethics, there will always be poorly asked questions or questions that cannot be answered within the acceptable realm of ethical trials. Therefore, there will always be a small percentage of research proposals that will not be able to obtain ethical clearances for these reasons. What this "small" percentage is, and whether it varies by country, research topic, the nature of IRBs, and other related questions would need a more detailed exploration than this survey offered.

\section{CONCLUSION}

This empirical work shows that researchers in the developing world have valuable experience with international and local ethical reviews, which contribute to global thinking on these 
issues. The researchers have reported that the review process generally happens and the proportion for US funded studies is not significantly different from non-US funded studies; however, there are gaps in the review process, which can result in a number of research projects not being reviewed. Therefore, the capacity to conduct ethical review in developing countries needs to be developed or enhanced. It is heartening to note that there are different models of such capacity development in existence today. These include the development of regional fora (such as the Pan African Bioethics Network) and training programmes for research ethics funded by Fogarty International Center of the National Institutes of Health, USA.

Although developing country researchers have acknowledged the ethical standards of US guidelines, they have indicated a need for international guidelines for collaborative and multinational research projects. In addition, the nature and process of review done by existing IRBs, in both developed and developing countries, can be improved. Finally, it is time that the views of developing country researchers play a vital role in determining the nature and type of ethical guidelines used in international collaborative research.

\section{Authors' affiliations \\ A A Hyder, S A Wali, A N Khan, N B Teoh, N E Kass, L Dawson, Bloomberg School of Public Health, Johns Hopkins University, Baltimore, $M D$, USA}

\section{REFERENCES}

1 Angell M. Ethics of clinical research in third world. N Engl J Med 1997;337:847-9.
2 Cleaton-Jones PE. An ethical dilemma: availability of antiretroviral therapy after clinical trials with HIV infected patients are ended. BMJ 1997;314:887-91.

3 Barry $\mathbf{M}$. Ethical considerations of human investigation in developing countries: the AIDS dilemma. N Engl J Med 1988;319:1083.

4 Angell $M$. Ethical imperialism-ethics in international collaborative clinical research. N Engl J Med 1988;319:1081-3.

5 Farmer P. Can transnational research be ethical in developing world? Lancet 2000:360:1266.

6 Porter L, Gostin L. The application of United States protection of human subjects regulations and ethical principles to United States funded or conducted HIV-related research in foreign countries, (Georgetown University, 1994, unpublished)

7 Wichman A, Smith J, Mills D, et al. Collaborative research involving human subjects: a survey of researchers using international single project assurances. IRB 1997;19:1-6

8 Phanuphak P. Ethical issues in studies in Thailand of the vertical transmission of HIV. N Engl J Med 1998;338:834-5.

9 Bayer R. The debate over maternal-fetal HIV transmission prevention trials in Africa, Asia, and the Caribbean: Racist exploitation or exploitation of racism. Am J Public Health 1998;88:567-70.

10 Annas GJ, Grodin MA. Human rights and maternal-fetal HIV transmission prevention trials in Africa. Am J Public Health 1998;88:560-3.

11 Palca J. African AIDS: Whose research rules? Science 1990;250:199-201.

12 Levine RJ. Informed consent: some challenges to the universal validity of the Western model. Law Med Health Care 1991;19:207-13.

13 Wilmhurst P. Scientific imperialism. BMJ 1997:314:840.

14 The Council for International Organizations of Medical Sciences (CIOMS). International ethical guidelines for biomedical research involving human subjects. Geneva, Switzerland: The Council for International Organizations of Medical Sciences (CIOMS), 2002.

15 Nuffeild Council on Bioethics. The ethics of research related to health care in developing countries. London, UK: Nuffield Council on Bioethics, 2002.

16 National Bioethics Advisory Commission, Rockville MD, Ethical and Policy Issues in International Research, 2000 Available from http:// www.georgetown.edu/research/nrcbl/nbac/pubs.html.

17 World Health Organization (WHO) Ad Hoc Committee on Health Research Relating to Future Intervention Options. Investing in health research and development. Geneva, Switzerland: World Health Organization (WHO), 1996.

18 Gostin L. Ethical principles for the conduct of human subject research: population-based research and ethics. Law Med Health Care $1991 ; 19: 191-201$.

\section{$\mathrm{ECHO}$}

\section{French doctors want euthanasia to be legalised}

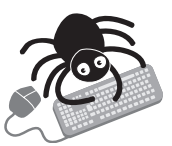

Please visit the Journal of Medical Ethics website [www. jmedethics. com]for a link to the full text of this article.
A any French doctors want euthanasia to be legalised, according to a nationwide telephone survey in France. This may be the result of a lack of professional knowledge about palliative care rather than cultural differences to English speaking countries.

A group of investigators interviewed a random sample of 917 doctors in France. They investigated respondents' involvement in end of life care and palliative care, their attitude towards terminally ill patients, and whether euthanasia should be legalised.

They found that general practitioners and neurologists were more in favour of euthanasia than oncologists, who are more experienced in end of life care, more frequently trained in palliative care, and more comfortable with and better at communication with terminally ill patients.

The investigators expressed surprise at their findings. Proponents of legalisation often argue that euthanasia is a continuation of end of life care and that doctors should respect patients' autonomy, and they therefore expected to find the reverse. Improving doctors' knowledge on palliative care might improve end of life care and may clarify the debate over euthanasia.

A BMJ 2003;327:595-596. 